\title{
The Use of Sandplay Therapy in Urban Elementary Schools as a Crisis Response to the World Trade Center Attacks
}

\author{
Christine J. Yeh, Sara M. Aslan, Violeta E. Mendoza, Mio Tsukamoto \\ University of San Francisco, San Francisco, USA
}

\begin{abstract}
We evaluated the use of sandplay therapy with a sample of 32 elementary school students, who were evacuated from school during the World Trade Center Attacks of September 11, 2001. We collected qualitative and quantitative data on each of the students who participated in sandplay therapy. Qualitative data included detailed case notes and photos from each sandplay session with the students. Quantitative data included academic and school-based preand post-test data. Results reveal student improvements in test scores, counselor and teacher ratings, attendance, behavioral referrals suspensions, and counseling status. Finally, we offer recommendations for the use of sandplay therapy as a means for helping culturally diverse children psychologically, socially, emotionally, and academically.

Keywords: sandplay therapy, World Trade Center Attacks, urban elementary schools, crisis response
\end{abstract}

Sandplay is a psychotherapeutic tool that combines the patient's creation of a picture, or miniature world in a tray of sand in the presence of a trained therapist; a non-verbal approach to therapy that reaches a profound preverbal level of the psyche (Weinrib, 1983). The essentials of sandplay therapy consist of two specific size sandtrays (one wet and one dry) that are painted blue on the bottom and the sides to represent Earth's waters and atmosphere (Preston-Dillon, 2008). Shelves of miniatures of multitude variety: people, animals, buildings, bridges, vehicles, furniture, food, plants, rocks, shells, and so on. Throughout the sandplay process, an empathetic therapist provides freedom and the protection that encourages the client to experience their inner, often unrealized selves in a safe and non-judgmental space. The therapist is seen as a "silent witness" who "appreciates" and "does not judge" what the client creates. It is vital that the therapist follows the play and stays in tune with it, but does not interrupt the process (Bradway \& McCoard, 1997).

During the creation of the sandplay scene, interpretation of the tray is delayed until a series of trays has been completed, over a period of time, so that the process can unfold naturally without interference from the therapist. Photographs or sketches of each completed tray may be taken and reviewed by the client and therapist together. This collaborative review process is said to bring a new level of awareness when the sandplay experience is combined with cognitive awareness (Mitchell \& Friedman, 1994).

\section{Stages of Sandplay Therapy}

Weinrib (1983) believed stages of sandplay do not appear as clear and distinct entities or in a specific

Christine J. Yeh, Ph.D., Department of Counseling Psychology, School of Education, University of San Francisco.

Sara M. Aslan, M.A., Department of Counseling Psychology, School of Education, University of San Francisco.

Violeta E. Mendoza, M.A., Department of Counseling Psychology, School of Education, University of San Francisco.

Mio Tsukamoto, M.A., Department of Counseling Psychology, School of Education, University of San Francisco. 
order. The general process of sandplay is more like a spiral where the elements of the personality are presented in a symbolic form during different levels of development. Though there are differences between the seven stages of the sandplay therapy process, they do overlap and merge together.

The first stage of development, "Problems and Resolutions" is described as a sandplay picture having realistic scenes where they may provide signals of problems and possible solutions. The second stage, "Descent into Depths" provides images that may have a chaotic feature to them; many times indicating deeper levels of the personality (personal unconscious). The third stage, "Centering", may usually be represented in images of unions of opposites, for instance religious symbols such as Buddha and Christ together. "Relativization of the Ego to the Self", a phenomenon coined by Kalff (1980), is the fourth stage where the "patient's consciousness (ego) having experience the greater Self, gives up its autonomy, and at the same moment, paradoxically experiences itself as strong, due to a feeling of being supported by that same transpersonal power to which it is surrendered" (Weinrib, 1983, p. 85). This stage becomes most apparent when the client is able to view the slides and experience what has taken place within him or herself. From there, a new relationship has developed within the client and a new sense of worth and strength becomes visible.

The fifth stage called "the Activation of the re-born Ego" is described as a phase when the client may find a miniature figure which he or she consciously identifies with and is present during the ongoing process. During this sandplay process the patient consciously recognizes that the figures are symbols for aspects of themselves and that they can interact and use them for self-expression (Weinrib, 1983). The sixth stage, called "Activation of the Animal/Animus", is when figures or symbols of the opposite sex are present frequently; this points toward the differentiation and activation of the masculine-feminine, contra sexual animus/anima factors. The last and final stage, "Ego Development", appears to have three different appearances: earth-water and vegetative symbols, patriarchal sky-sun symbols, and the appearance of patriarchal symbolism in the pictures of both men and women, marking the beginning of an independent ego. Though there are several different theories regarding the stages of a sandtray, some therapists believe a tray should be viewed holistically rather than divided in sections and categories.

\section{Mitchell and Friedman (1994) Themes in Sandplay}

When a therapist or counselor is viewing a client's sandplay scene, their role is to provide a silent, respectful acceptance of the images created during the sandplay process, as a result, allowing the client to feel increasingly safe and free. Mitchell and Friedman (1994) believe there are five main considerations that dominate the field of sandplay therapy:

(1) How the sandtray is created. It is important for a counselor or therapist to observe how interested or resistant their client may be when creating their tray. Also, it is important to be aware of how sand and water are being used, where miniatures are placed, how the client is expressing his emotions such as, anxiety, fears, or excitement, and where the client is standing in relation to the tray, all essential observations should focus on understanding how the tray is created.

(2) The content of the tray. The tray's content should be followed and recorded using photographs or sketches where the therapists takes note of symbolic meanings of the objects, the shapes that emerge by using sand and miniatures, and the placement of the figurines. In addition, understanding the different developmental stages present in sandtray.

(3) Sandplay series. Being aware of how the clients' tray is evolving over time and noticing certain 
symbols being used repeatedly and how their location is changing.

(4) Sandplay story. Paying attention to the themes, stories, emotional implications and symbolic content can provide insight to the client's internal process.

(5) Therapist's feeling response. A significant piece to be considered is when the therapist is able to listen to his/her own feeling response during the making of the sandtray. This feeling response can provide a deeper understanding and important information to understand the client's process. These personal thoughts and feelings should be encouraged and included in understanding the process of the client's sandtray.

Along with the five main considerations dominating the field of sandplay, Mitchell and Friedman (1997) researched sandplay themes and found two main themes expressed in the healing process. "Wounding" was the first theme and was found most common in trays of clients who had experienced trauma, abuse, loss, or illness. "Healing (or transformational)" was the second theme found mostly in clients who had healthy, less traumatic lifestyles and who were in the latter phases of therapy.

Furthermore, Mitchell and Friedman (1997) discovered that the amount of healing and wounding themes changed as therapy progressed. For instance, during the initial stages of therapy, wounding themes were more prominent than healing themes; however, as therapy sessions progressed, new themes of healing appeared and began to outnumber the wounding themes. Lastly, Mitchell and Friedman (1997) found that both wounding and healing themes would develop and evolve during the sandplay process.

\section{Sandplay in Schools}

Sandplay and various creative play therapies have been applied in schools to help teachers and school counselors facilitate learning as well as psychological development and healing. Sandplay has been an accepted counseling technique used in schools in part because schools understand that playing in the sand can help facilitate the developing physical, social, and academic abilities of children (Mitchell \& Friedman, 1994). According to Mitchell and Friedman (1994):

Sandplay techniques fit well into the theoretical approach of many schools due to the fact that the training of many school counselors is humanistically oriented; emphasizing the Rogerian view of unconditional positive regard which is similar to respectful witnessing in sandplay therapy. (p. 102)

Sandplay may also be used in school settings to help students release blocked energies and activate their self-healing potential (Mitchell \& Friedman, 1994). For these reasons, several post 9/11 New York City schools taught and supervised counselors in using sandtrays as they worked with traumatized children and adults (Winter, 2008). Another example is Mary Noyes, a former school teacher who conducted sandplay in her classroom on a one-to-one basis. Noyes (1981) reported that the sandplay experience deepened rapport and intimacy, improved self-esteem, helped resolve inner conflicts and helped improve her students reading level (Mitchell \& Friedman, 1994). Aside from individual sandtray therapy sessions, group sandtray therapy has also been used with different groups of students such as young adolescent girls to help develop self-esteem (Shen \& Armstrong, 2008). Furthermore, according to Lu, Petersen, Lacroix, and Rousseau (2010), through sandplay, children with autism spectrum disorders in schools demonstrated an increase in verbal expression, engaged and sustained social interaction, and increased symbolic, spontaneous, and novel play. These therapy techniques have also aided developmentally with younger children as well as those in adolescents. Children in the 5-8 year range, showed a transition from preoperational to concrete operational thought, whereas adolescents, 12-18 
years of age, operated from a concrete to abstract orientation (Russo, Vernam, \& Wolbert, 2006).

\section{Use of Sandplay for Culturally Diverse Children and Youth}

Sandplay continues to be incorporated in schools where counselors and teachers find the sandtray to be a very useful technique when working with non-English-speaking children, as it is one of the few therapeutic methods that do not rely solely on verbal language. Previous research has suggested that nonverbal expression of emotions and actions has a more immediate effect than the use of language (Cook et al., 2005; Lusbrink, 2004; Yeh et al., 2015). In addition, sand provides a tactile and sensory experience (Lacroix, 2002), which can create a calming and relaxing effect. Art in various forms such as drawing, painting, sandplay making, sculpting and so on, can aid students to represent their emotions in a direct manner. Art making then becomes a useful way to help exposed children release and deal with their traumatic experiences (Steele, 2006).

Schools today must meet the complex social, cultural, linguistic, economic, emotional, and academic needs of their students that come from diverse and cross-cultural groups, a multidimensional challenge that can bring enrichment as well as great misunderstanding in schools. For teachers and school counselors this situation can be quite difficult, given that understanding their students' language and culture can create various barriers. Sandplay is one of the few therapeutic approaches where language is not essential. It is a valuable, primarily nonverbal, technique for working with students who have language barriers and offers many opportunities to express a wide range of emotions nonverbally through various uses of sand.

For example, sandplay therapy was used with immigrant and refugee South Asian preschoolers who were indirectly affected by a tsunami tragedy in their home country (Lacroix, Rousseau, Gauther, Singh, Giguere, \& Lemzoudi, 2007). In this project, students were able to express their emotions about the disaster through symbolic objects. In addition, using the miniatures in the sandplay they could try to cope and make sense of the tragic event. The study was completed in Montreal, Canada where there has been a large population of South Asian immigrants. Over 50 students, ages four and five, participated in eight 60-minute sandplay sessions. The topics explored included the following: Relationships with family, relations with siblings, language spoken at home, seasons, favorite foods, favorite celebrations, and favorite animals. The students selected from a variety of traditional sandplay figurines including people, animals, structures, food and so on. There were also symbols that represented a diverse group of cultures and figurines such as people in national costumes, flags of their country, and religious symbols (Lacroix et al., 2007; Rousseau, Lacroix, Singh, Gauthier, \& Benoit, 2005).

Throughout the study, about a third of the children utilized symbols representing the tsunami in non-verbal or verbal representations. Moreover, these children had utilized coping strategies in which they would include the use of traditional figurines such as gods, deities, and angels. These symbols were seen as rescuers and heroes. Overall, this study demonstrated that activities of creative and artistic expression in schools can provide students with an environment for symbolic expression and playful exploration. This resulted in enhanced resiliency factors for immigrant students suffering from anxiety, depression, trauma and adjustment (Lacroix et al., 2007; Rousseau et al., 2005).

\section{Sandplay in Response to the World Trade Center (WTC) Attacks}

For decades sandplay has been used to address various issues in children and adults. Some of these problems addressed by therapists include but are not limited to: depression (Yamanaka, 1982), grieving children (Mantele, in press), learning problems (Reed, 1975), enuresis nocturna (Kimura, 1982), schizophrenia 
(Takano, 1982), speech problems (Kalff, 1980), battered and isolated children (Takano, 1982), anxiety (Kalff, 1980), selective mutism (Xu \& Zhang, 2008), ADHD (Xu, R. Zhang, \& W. Zhang, 2008), Oppositional Defiant Disorder (Shih, Kao, \& Wang, 2006), and many more. Sandplay offers a unique way to help provide the client with a place to work through many phases of self-healing and development.

Sandplay therapy is especially important to consider for crisis situations such as the WTC Attacks on September 11, 2001. After the attacks occurred, children were in need of an intervention due to being in view of the WTC and evacuated from their schools and homes. Counselors faced serious challenges in deciphering the most effective intervention to use with these children since they, especially those of minority backgrounds, tend to cope with grief or loss using nonverbal and creative outlets versus more traditional forms of direct, verbal expression (Borrero, Yeh, Tito, \& Luavasa, 2010; Yeh, Borrero, Tito, \& Petaia, 2014). Asian American youth, for example, often feel cultural stigmas and embarrassment when dealing with emotional difficulties such as pain and loss (Shea \& Yeh, 2008). For these reasons, Sandplay therapy appeared to be most relevant for coping with the WTC crisis since it provides a nonverbal method of dealing with problems, fears, grief, and emergent issues (Yeh, Kim, Pituc, \& Atkins, 2008).

Sandplay therapy has become a widely used form of treatment in Japan, due to the protective free space and playful self-discovery it provides (Kitanaka, 2003). Prior research has indicated that the families of immigrant preschoolers who have experienced adversity before migration can benefit from creative expressive workshops such as sandplay (Rousseau, Benoit, Lacroix, \& Gauthier, 2009). It provides children and adults with an opportunity to convey and work through their ideas and emotions in a creative, expressive manner, both verbally and nonverbally. Through the years, studies have demonstrated many children have benefited from sandplay therapy to make sense of their past and present experiences. Thus, sandplay was implemented as a direct response to alleviate the extreme grief and trauma experienced by children and youth in the Chinatown area—due to their close proximity to the World Trade Center.

\section{Research and Hypothesis}

We believed that sandplay would be an excellent tool to use with children who had experienced the trauma of $9 / 11$ because it requires minimal or no use of traditional talk therapy. The current evaluation focuses on the use of sandplay therapy with a sample of culturally diverse children in several elementary schools in New York City. We were interested in assessing academic, psychological, and behavioral outcomes before and after students' participation in sandplay sessions at their school to insure that it is a valid and effective means for facilitating positive student development. In particular, we explored the following main research questions:

What are the main "wounding" and "transformational" themes that emerge from the sandplay sessions?

What are other sandplay themes that emerge for the students in our sample?

In particular, did themes associated with the World Trade Center Attacks emerge during the sandplay sessions?

Do students' English language and math standardized test scores increase after involvement in sandplay sessions?

Do counselors' and teachers' ratings of students increase after their participation in sandplay sessions?

Do students' number of behavioral referrals and suspensions decrease after participation in sandplay sessions? 
We expected that sandplay sessions would have a positive impact on students' academic, behavioral, and psychological outcomes. Specifically, we expected students to have increased English language and math scores, counselor and teacher ratings, counseling status, and improved attendance as a result of this therapeutic intervention. Similarly, we also hypothesized that student' behavioral referrals and suspensions would decrease as a result of participating in sandplay sessions.

\section{Method}

\section{Participants}

Participants included 32 students (17 male and 15 female) from five different public elementary schools in New York City. In terms of grade level, five of the students were in kindergarten, four in first grade, six in second, third, fourth grades, and three in fifth grade. Seventeen of the students were Asian, eight were biracial, five were black, and one was Hispanic. Among all the students, 46.9\% (15) had English as a first language, $43.8 \%$ (14) spoke Chinese as a first language, two spoke Spanish and one did not report first language.

\section{Counselors}

Six female counselors from five schools served as sandplay therapists for the 32 cases covered. All counselors were female and all have at least a Masters Degree in Education, Psychology, Social Work, or Marriage and Family Therapy. Four of the counselors identified as Chinese-American and two were White European-American and their ages ranging from 30 to 61 years $(M=47.67)$. They had spent an average of 9.67 years at the school (range $=4-15$ ). All of the counselors have had training in sandplay therapy.

\section{School Setting}

All of the schools in the sample are in New York City Chinatown, which is a densely populated urban section of Manhattan. This particular location is highly relevant due to its geographic proximity to the World Trade Center Attacks. Specifically, after the September 11th attacks, many of the business in Chinatown were closed, deeply impacting the economy and community spirit. The surrounding population is predominantly comprised of Chinese-Americans and Chinese immigrants. Most of the students are from low-income families who work in the local community in the service industry (restaurant workers, factories, etc). The schools have strong principals, very low staff turnover, and work hard to respond to the students' social and educational needs.

\section{Training in Sandplay Therapy}

Before the counselors worked with their individual student caseloads, they all participated in intensive clinical training in sandplay therapy. This training consisted of a total of 156 hours of seminars, speakers, practice, lecture, and clinical activities. Table 4 provides an overview of the training activities and hours involved. In addition to the training sessions and speaker series listed, the counselors had 65 hours of group and individual supervision. They also had to experience sandplay therapy on their own, totaling an approximation of 50 hours of personal process.

\section{Procedure}

The primary research team consisted of three females, one Chinese-American (Professor in Counseling Psychology) and two White European-American (one school counselor and one Counseling Advisor and 
Supervisor of Special Projects). The research team met frequently to discuss the research questions, themes of interest, coding procedures, and expected outcomes. During these meetings, we also discussed the relevant literature on sandplay techniques and theory and determined the specific areas of scrutiny and coding themes. We were especially interested in the themes created by Mitchell and Friedman (1997) and believed they would help us to understand the students' internal healing process and difficult psychological experiences.

We collected qualitative and quantitative data on each of the 32 elementary school cases that had participated in sandplay therapy. Qualitative data included detailed case notes and photos from each sandplay session with the students. Quantitative data included English language and math scores, counselor and teacher ratings of students, attendance, behavioral referrals, suspensions, and counseling status.

\section{Coding}

Each of the sandplay sessions was coded by a trained research assistant using the Mitchell and Friedman (1994) Wounding and Transformational themes. The ten "Wounding" themes include: "chaos, empty, split, confused, neglected, hidden, prone, injured, threatened, and hindered". The ten Transformational themes include: "bridged, journey, energy, deepened, birthed, nurtured, changed, spiritual, centered, and integrated". Each theme is defined in Tables 1 and 2. These tables also include examples of each theme.

In addition to the Mitchell and Friedman (1994) themes described above, each sandplay session was also coded for nine general themes that were developed by the research team to investigate particular areas of interest. These additional themes are self-explanatory and include: "chaos/loss, struggle, resolution, self, cultural (themes relating to student's cultural background), lack of connection to others, connection to family, World Trade Center Symbols (many of the students recall the World Trade Center Attacks), and symbols of support (emotional and social support)". As stated, we were especially interested in any themes relating to the World Trade Center Attacks that may emerge in the sandplay sessions.

Table 1

Mitchell and Friedman (1997) Wounding Themes

\begin{tabular}{|l|l|l|}
\hline Themes & Description & Examples \\
\hline Chaotic & Haphazard, fragmented or formless arrangement & $\begin{array}{l}\text { Objects flung into the tray, boundaries or outer reality } \\
\text { disregarded, overall appearance ins jumbled/disconnected }\end{array}$ \\
\hline Empty & $\begin{array}{l}\text { Reticence to use figures or lifeless feeling with lack of } \\
\text { energy and curiosity }\end{array}$ & $\begin{array}{l}\text { Nearly empty tray with only one dead tree placed in a } \\
\text { corner }\end{array}$ \\
\hline Split & Parts of tray appear separated or detached & $\begin{array}{l}\text { River, fence, or elephants placed from bottom to top of tray } \\
\text { seem to divide tray }\end{array}$ \\
\hline Confined & Figure or groups normally free are entrapped or caged & $\begin{array}{l}\text { An agonized figure is placed in a cage; a sand wall is built } \\
\text { around an old woman }\end{array}$ \\
\hline Neglected & Figure is isolated from possible support & $\begin{array}{l}\text { A baby in a high chair while mother is sleeping in the next } \\
\text { room }\end{array}$ \\
\hline Hidden & Figures buried or hidden from view & $\begin{array}{l}\text { A gun hidden behind a house; a witch buried in the sand } \\
\text { under a tree }\end{array}$ \\
\hline Prone & $\begin{array}{l}\text { Figures normally upright are intentionally placed in } \\
\text { reclining, fallen position }\end{array}$ & A standing pregnant woman placed face down in the sand \\
\hline Injured & Figures with injuries or in the process of being injured & $\begin{array}{l}\text { A bandaged man lying on a stretcher; a cowboy placed in } \\
\text { the mouth of a dinosaur }\end{array}$ \\
\hline Threatened & $\begin{array}{l}\text { Menacing or frightening events \& the ability of the } \\
\text { endangered figures to meet the experience }\end{array}$ & Aggressive animals surrounding a small child \\
\hline Hindered & Possibility of new growth is impeded or hindered & $\begin{array}{l}\text { A boat moving into new waters, while under siege by an } \\
\text { army }\end{array}$ \\
\hline
\end{tabular}


Table 2

Mitchell and Friedman (1997) Transformational Themes

\begin{tabular}{|c|c|c|}
\hline Themes & Description & Examples \\
\hline Bridging & Connection between elements, joining of opposites & $\begin{array}{l}\text { A ladder joins earth and tall trees; a bridge links an angel } \\
\text { and devil }\end{array}$ \\
\hline Journeying & Movement along a path or around a center & $\begin{array}{l}\text { A knight follows a trail; a Native American paddles a canoe } \\
\text { down a stream }\end{array}$ \\
\hline Energy & Alive, vital, intense energy is visible & $\begin{array}{l}\text { Organic growth present, construction machines work on a } \\
\text { task, airplanes take off from a runway }\end{array}$ \\
\hline \begin{tabular}{|l|l|} 
Going \\
Deeper
\end{tabular} & Discovery of a deeper dimension & $\begin{array}{l}\text { A clearing is made, a treasure unearthed, a well dug, a lake } \\
\text { explored }\end{array}$ \\
\hline Birthing & Emergence of a new development & A baby is born, a flower opens, a bird incubates eggs \\
\hline Nurturing & $\begin{array}{l}\text { Nourishment or help are provided to support growth } \\
\text { and development }\end{array}$ & $\begin{array}{l}\text { A mother feeding babies, supporting family groups, nurse } \\
\text { helps a patient, presence of food }\end{array}$ \\
\hline Changed & Sand and/or objects are creatively changed or used & $\begin{array}{l}\text { Sand is contoured to build a land bridge; sand is } \\
\text { moved/stacked as an essential part of a lunar compound, a } \\
\text { house is built from twigs picked up on a walk to school }\end{array}$ \\
\hline Spiritual & $\begin{array}{l}\text { Religious or spiritual symbols present, such as } \\
\text { supernatural beings, worshipping figures or numinous } \\
\text { items }\end{array}$ & Buddha overlooking newly married couple \\
\hline Centered & $\begin{array}{l}\text { In center of a tray, elements are aesthetically balanced } \\
\text { or a union or opposites occurs }\end{array}$ & A man and woman married; mandala centered in the tray \\
\hline Integrated & $\begin{array}{l}\text { Congruent, organized idea encompasses entire tray, } \\
\text { unity of expression }\end{array}$ & $\begin{array}{l}\text { Day at the zoo, ba } \\
\text { unifying whole tray }\end{array}$ \\
\hline
\end{tabular}

Table 3

Student Demographic Information

\begin{tabular}{|c|c|c|c|c|c|c|c|}
\hline \multirow{3}{*}{$\begin{array}{l}\text { Variable } \\
\text { Gender } \\
\text { Grade in School }\end{array}$} & \multicolumn{7}{|c|}{ Frequency } \\
\hline & \multicolumn{3}{|c|}{ Male 17(53.1) } & \multicolumn{4}{|c|}{ Female 15(46.9) } \\
\hline & $\begin{array}{l}\text { K } \\
5(15.6)\end{array}$ & $\begin{array}{l}1 \mathrm{st} \\
4(12.5)\end{array}$ & $\begin{array}{l}\text { 2nd } \\
6(18.8)\end{array}$ & $\begin{array}{l}\text { 3rd } \\
6(18.8)\end{array}$ & $\begin{array}{l}\text { 4th } \\
6(18.8)\end{array}$ & $\begin{array}{l}5 \text { th } \\
3(9.4)\end{array}$ & $\begin{array}{l}\text { N/A } \\
2(6.3)\end{array}$ \\
\hline School & $\begin{array}{l}\text { PS 1 } \\
10(31.2)\end{array}$ & $\begin{array}{l}\text { PS 2 } \\
1(3.1)\end{array}$ & $\begin{array}{l}\text { PS 42 } \\
10(31.2)\end{array}$ & $\begin{array}{l}\text { PS 124 } \\
6(18.7)\end{array}$ & $\begin{array}{l}\text { PS 130 } \\
2(6.3)\end{array}$ & $\begin{array}{l}\text { N/A } \\
3(9.4)\end{array}$ & \\
\hline Race & $\begin{array}{l}\text { Asian } \\
17(53.1)\end{array}$ & $\begin{array}{l}\text { Black } \\
5(15.6)\end{array}$ & $\begin{array}{l}\text { Hispanic } \\
1(3.1)\end{array}$ & $\begin{array}{l}\text { Biracial } \\
8(25.0)\end{array}$ & $\begin{array}{l}\text { N/A } \\
1(3.1)\end{array}$ & & \\
\hline First Language Spoken & $\begin{array}{l}\text { English } \\
15(46.9) \\
\end{array}$ & $\begin{array}{l}\text { Chinese } \\
14(43.8)\end{array}$ & & $\begin{array}{l}\text { Spanish } \\
2(6.3)\end{array}$ & & $\begin{array}{l}\mathrm{N} / \\
1(\end{array}$ & \\
\hline
\end{tabular}

Table 4

Counselor Sandplay Therapy Training Program

\begin{tabular}{|c|c|c|c|}
\hline Month & Activity & Topics & Hours \\
\hline 1 & Introduction to Sandplay & $\begin{array}{l}\text { History } \\
\text { Symbols, signs, archetypes } \\
\text { Creation of images on psyche } \\
\text { Play } \\
\text { Jungian theory/projection } \\
\text { Sandplay collection }\end{array}$ & 7 \\
\hline 2 & $\begin{array}{l}\text { Introduction to Sandplay } \\
\text { Part II }\end{array}$ & $\begin{array}{l}\text { Symbolic process/relationship to the unconscious/function } \\
\text { Preverbal expression } \\
\text { Structure and the layers of the psyche } \\
\text { What might appear in the sand } \\
\text { First trays } \\
\text { Themes in sandtrays }\end{array}$ & 7 \\
\hline 3 & STA training process & $\begin{array}{l}\text { Temenos } \\
\text { Therapeutic dyad/ transference/counter transference } \\
\text { Archetypal grids of healing and growth }\end{array}$ & 7 \\
\hline
\end{tabular}


Table 4 continued

\begin{tabular}{|c|c|c|c|}
\hline Month & Activity & Topics & Hours \\
\hline 4 & Symbolic work & $\begin{array}{l}\text { Learning to be symbolic/symbol work } \\
\text { The sandplay journey } \\
\text { Wet trays/dry trays? } \\
\text { Fairytales } \\
\text { Stages of the sandplay process }\end{array}$ & 7 \\
\hline 5 & Symbol presentation & $\begin{array}{l}\text { The seal by Darcy Ortolf } \\
\text { Trauma in trays } \\
\text { Transformation of complexes } \\
\text { Jungian theory } \\
\text { Complex theory } \\
\text { Alchemical processes/solution } \\
\text { Applied Jung: play/sandplay/art }\end{array}$ & 6 \\
\hline 6 & Cultural issues & Interracial and biracial awareness/cases material speaker: Tessamarie capitolo & 7 \\
\hline 7 & Colloquium & Colloquium-self tray & 3 \\
\hline 8 & Adoption and abandonment & $\begin{array}{l}\text { "When the bough breaks" } \\
\text { Adoption and abandonment cases } \\
\text { Speaker: Betty Jackson }\end{array}$ & 4 \\
\hline 9 & The Work of Jung & $\begin{array}{l}\text { Jungian theory/shadow } \\
\text { Transference around a highly charged symbol } \\
\text { Working with a symbol/ } \\
\text { Writing symbol paper }\end{array}$ & 7 \\
\hline 10 & Defenses & $\begin{array}{l}\text { The function of images and symbols in the psyche } \\
\text { Defenses } \\
\text { Ego defenses and defenses of the self, and their manifestation in the tray }\end{array}$ & 6 \\
\hline 11 & Writing a symbol paper & $\begin{array}{l}\text { The witch } \\
\text { The superhero } \\
\text { Speaker: Sally Sugate }\end{array}$ & 6 \\
\hline 12 & Gender and development & $\begin{array}{l}\text { Gender and age developmental norms in children's sandplay and adult's } \\
\text { regressive trays } \\
\text { Speaker: Harriet Friedman }\end{array}$ & 6 \\
\hline 13 & Symbol certification & Organization and preparation for symbol formation certification & 3 \\
\hline $14-25$ & Speaker series & Various experts in the sandplay therapy field & 33.5 \\
\hline
\end{tabular}

\section{Results}

The main decision to use sandplay in the various urban school settings was to focus on elementary school-aged children who had experienced the tragedy of $9 / 11$. We found as a result of using sandplay in many of our downtown schools that the nonverbal aspect of the therapy served a dual purpose in reaching a population that had either limited English language or a cultural hesitancy toward traditional talk therapy. As mentioned previously, many Asian immigrants and Asian Americans may feel embarrassed about how to talk about painful emotional topics (Inman, Yeh, Madan-Bahel, \& Nath, 2007; Yeh, Inman, Kim, \& Okubo, 2006). These feelings of stigma were exacerbated by the unexpected and severity of the World Trade Center Attacks.

Our findings reveal significant improvements in terms of academic, psychological, and behavioral outcomes before and after the 32 students' participation in sandplay sessions at their schools. Table 5 presents before and after data (means and standard deviations) from the sample. Using school records, we collected data on students' average English language and math standardized test scores. As expected, we found that students had a mean English Language score of $636.70(S D=21.12)$ before sandplay sessions and a mean score of $677.46(S D=34.67)$ for an increase in 40.76 points total. In addition, counselor ratings of students in sandplay therapy also increased almost $100 \%(1.82$ points $)$ from an average of $1.86(S D=0.76)$ to $3.68(S D=1.09)$ 
following their sandplay sessions. Teachers' ratings of the students also improved from $2.15(S D=0.91)$ to $3.59(S D=0.93)$ following the sandplay sessions.

Students' behavioral outcomes also improved as a result of the sandplay sessions. For example, the average number of students' absences decreased from $7.25(S D=6.65)$ to $2.33(S D=1.16)$, number of behavioral referrals also decreased from $2.60(S D=4.19)$ to $0(S D=0)$, and the number of student suspensions decreased from $0.28(S D=1.07)$ to $0.04(S D=0.19)$. Finally, students' status in counseling improved from a rating of $1.64(S D=0.49)$ to $2.43(S D=1.34)$.

\section{Wounding and Transformational Themes}

Each session for each of the 32 students was also coded for wounded and transformational themes as based on the work of Mitchell and Friedman (1994). Descriptive statistics frequency counts were used to determine the number of themes across each session. In total, there were 522 wounding themes and 499 transformational themes. As expected, the wounding themes were more prevalent in the beginning then eventually decrease in the later sessions indicating that the healing process is underway (Mitchell \& Friedman, 1994). As shown in Table 6, there were a total of 67 "wounding" themes in the first session, 54 in the fifth session, and only 33 total "wounding" themes by the eighth session. The most frequent wounding themes were "empty, hidden, and prone".

Table 5

Student Academic and Behavioral Outcomes

\begin{tabular}{lrrrc}
\hline & \multicolumn{2}{c}{ Pre } & \multicolumn{1}{c}{ Post } \\
\cline { 2 - 5 } & $M$ & $S D$ & 677.46 & 34.67 \\
\hline English language score & 636.70 & 21.12 & 682.46 & 50.61 \\
Math score & 649.56 & 50.55 & 0.04 & 0.189 \\
Number of suspensions & 0.28 & 1.07 & 2.33 & 1.155 \\
Attendance records & 7.25 & 6.65 & 0.00 & 0.000 \\
Number of behavioral referrals & 2.60 & 4.188 & 2.43 & 1.35 \\
Status of counseling & 1.64 & 0.488 & 3.68 & 1.09 \\
Counselor rating & 1.86 & 0.76 & 3.59 & 0.93 \\
Teacher academic rating & 2.15 & 0.91 & & \\
\hline
\end{tabular}

Table 6

Frequencies for Wounding, Transformational, and Sandplay Themes

\begin{tabular}{lccccccccc}
\hline Sessions & S1 & S2 & \multicolumn{1}{c}{ S3 } & S4 & S5 & S6 & S7 & S8 & Total \\
\hline Wounding & 87 & 92 & 83 & 68 & 54 & 61 & 44 & 33 & 522 \\
Chaos & $10(31.3)$ & $14(43.8)$ & $6(18.8)$ & $3(9.4)$ & $2(6.3)$ & $4(12.5)$ & $3(9.4)$ & $2(6.3)$ & 44 \\
Empty & $14(43.8)$ & $9(28.1)$ & $11(34.4)$ & $3(9.4)$ & $7(21.9)$ & $11(34.4)$ & $7(21.9)$ & $8(25.0)$ & 70 \\
Split & $5(15.6)$ & $4(12.5)$ & $8(25.0)$ & $3(9.4)$ & $1(3.1)$ & $4(12.5)$ & $2(6.3)$ & $2(6.3)$ & 29 \\
Confused & $5(15.6)$ & $7(21.9)$ & $6(18.8)$ & $3(9.4)$ & $5(15.6)$ & $4(12.5)$ & $2(6.3)$ & $1(3.1)$ & 33 \\
Neglected & $1(3.1)$ & $5(15.6)$ & $7(21.9)$ & $3(9.4)$ & $3(9.4)$ & $1(3.1)$ & $3(9.4)$ & $1(3.1)$ & 24 \\
Hidden & $17(53.1)$ & $16(50.0)$ & $10(31.3)$ & $13(40.6)$ & $10(31.3)$ & $14(43.8)$ & $10(31.3)$ & $5(15.6)$ & 95 \\
Prone & $13(40.6)$ & $11(34.4)$ & $11(34.4)$ & $17(53.1)$ & $7(21.9)$ & $9(28.1)$ & $6(18.8)$ & $6(18.8)$ & 80 \\
Injured & $6(18.8)$ & $10(31.3)$ & $8(25.0)$ & $9(28.1)$ & $6(18.8)$ & $2(6.3)$ & $3(9.4)$ & $4(12.5)$ & 48 \\
Threatened & $10(31.3)$ & $9(28.1)$ & $11(34.4)$ & $8(25.0)$ & $7(21.9)$ & $6(18.8)$ & $4(12.5)$ & $2(6.3)$ & 57 \\
Hindered & $6(18.8)$ & $7(21.9)$ & $5(15.6)$ & $6(18.8)$ & $6(18.8)$ & $6(18.8)$ & $4(12.5)$ & $2(6.3)$ & 42 \\
\hline
\end{tabular}


Table 6 continued

\begin{tabular}{|c|c|c|c|c|c|c|c|c|c|}
\hline Sessions & S1 & $\mathrm{S} 2$ & S3 & $\mathrm{S} 4$ & S5 & S6 & S7 & S8 & Total \\
\hline Transformation & 44 & 48 & 61 & 65 & 81 & 69 & 66 & 65 & 499 \\
\hline Bridged & $5(15.6)$ & $9(28.1)$ & $9(28.1)$ & $8(25.0)$ & $11(34.4)$ & $9(28.1)$ & $6(18.8)$ & $6(18.8)$ & 63 \\
\hline Journey & $2(6.3)$ & $6(18.8)$ & $5(15.6)$ & $9(28.1)$ & $7(21.9)$ & $10(31.3)$ & $6(18.8)$ & $7(21.9)$ & 52 \\
\hline Energy & $5(15.6)$ & $8(25.0)$ & $5(15.6)$ & $9(28.1)$ & $12(37.5)$ & $11(34.4)$ & $6(18.8)$ & $5(15.6)$ & 61 \\
\hline Deepened & $10(31.3)$ & $7(21.9)$ & $12(37.5)$ & $13(40.6)$ & 13(40.6) & $9(28.1)$ & $12(37.5)$ & $11(34.4)$ & 87 \\
\hline Birthed & $3(9.4)$ & $2(6.3)$ & $5(15.6)$ & $1(3.1)$ & $3(9.4)$ & $5(15.6)$ & $11(34.4)$ & $1(3.1)$ & 31 \\
\hline Nurtured & $0(0.0)$ & $3(9.4)$ & $1(3.1)$ & $3(9.4)$ & $5(15.6)$ & $3(9.4)$ & $4(12.5)$ & $5(15.6)$ & 24 \\
\hline Changed & $7(21.9)$ & $4(12.5)$ & $10(31.3)$ & $6(18.8)$ & $11(34.4)$ & $8(25.0)$ & $8(25.0)$ & $13(40.6)$ & 67 \\
\hline Spiritual & $9(28.1)$ & $7(21.9)$ & $7(21.9)$ & $7(21.9)$ & $12(37.5)$ & $10(31.3)$ & $7(21.9)$ & $6(18.8)$ & 65 \\
\hline Centered & $2(6.3)$ & $1(3.1)$ & $6(18.8)$ & $6(18.8)$ & $5(15.6)$ & $2(6.3)$ & $4(12.5)$ & $8(25.0)$ & 34 \\
\hline Integrated & $1(3.1)$ & $1(3.1)$ & $1(3.1)$ & $3(9.4)$ & $2(6.3)$ & $2(6.3)$ & $2(6.3)$ & $3(9.4)$ & 15 \\
\hline Sandplay theme & 55 & 83 & 71 & 76 & 76 & 74 & 58 & 52 & 545 \\
\hline Chaos/Loss & $18(56.3)$ & $17(53.1)$ & $12(37.5)$ & $9(28.1)$ & $6(18.8)$ & $8(25.0)$ & $5(15.6)$ & $6(18.8)$ & 81 \\
\hline Struggle & $6(18.8)$ & $7(21.9)$ & $14(43.8)$ & $9(28.1)$ & $11(34.4)$ & $6(18.8)$ & $6(18.8)$ & $6(18.8)$ & 65 \\
\hline Resolution & $0(0.0)$ & $0(0.0)$ & $0(0.0)$ & $2(6.3)$ & $1(3.1)$ & $3(9.4)$ & $0(0.0)$ & $3(9.4)$ & 9 \\
\hline Self & $3(9.4)$ & $2(6.3)$ & $2(6.3)$ & $0(0.0)$ & $6(18.8)$ & $4(12.5)$ & $4(12.5)$ & $2(6.3)$ & 23 \\
\hline Cultural & $4(12.5)$ & $4(12.5)$ & $2(6.3)$ & $5(15.6)$ & $8(25.0)$ & $5(15.6)$ & $4(12.5)$ & $4(12.5)$ & 36 \\
\hline Lack of connection & $17(53.1)$ & $24(75.0)$ & $22(68.8)$ & $20(62.5)$ & $15(46.9)$ & $15(46.9)$ & $7(21.9)$ & $8(25.0)$ & 128 \\
\hline $\begin{array}{l}\text { Connection } \\
\text { family }\end{array}$ & $2(6.3)$ & $5(15.6)$ & $3(9.4)$ & $6(18.8)$ & $8(25.0)$ & $15(46.9)$ & $4(12.5)$ & $7(21.9)$ & 50 \\
\hline World Trade Center & $2(6.3)$ & $7(21.9)$ & $2(6.3)$ & $6(18.8)$ & $5(15.6)$ & $3(9.4)$ & $5(15.6)$ & $2(6.3)$ & 32 \\
\hline Support & $3(9.4)$ & $17(53.1)$ & $14(43.8)$ & $19(59.4)$ & $16(50.0)$ & $15(46.9)$ & $23(37.5)$ & $14(43)$. & 121 \\
\hline
\end{tabular}

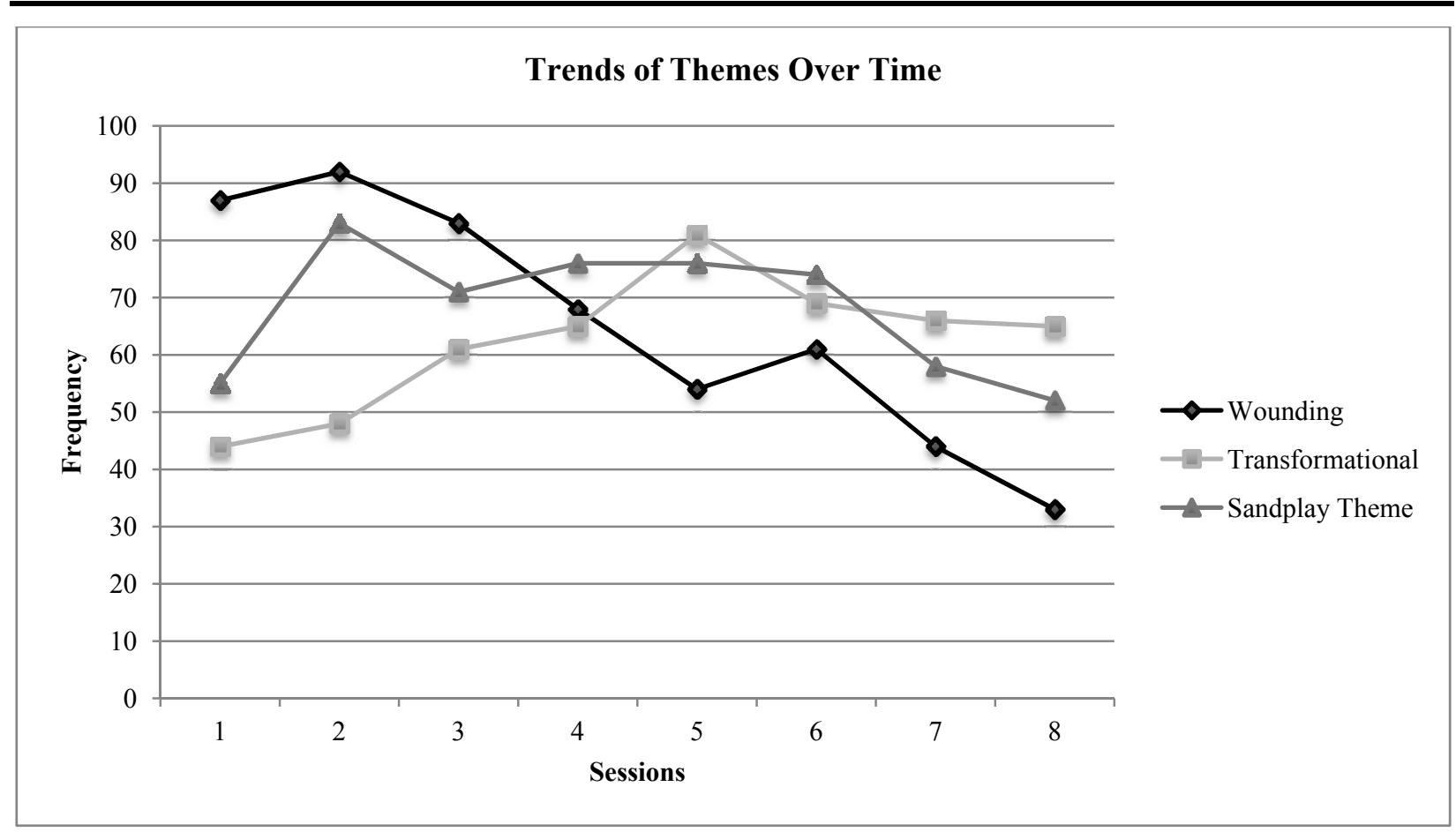

Figure 1. Wounding, transformational, and specific sandplay themes over time.

In terms of the transformational themes, it was expected that fewer transformational themes would present in the beginning sessions, and increase as the therapy continues. Our findings reveal that there were a total of 
44 transformational themes in the first session, 81 in the fifth session, and 65 in the eighth session. This partially meets our expectation in that the number of transformational themes was relatively low in the beginning and then increased during the course of the sandplay sessions. The most frequent transformational themes were "deepened, changed, and spiritual".

\section{Other Sandplay Themes}

It is also important to discuss how the counselors used sandplay to address issues related to $9 / 11$, similar to the discussion on the work done after the tsunami (Lacroix et al., 2007). Students in our sample were supplied with hundreds of figurines to choose from in using the sandtray including culturally significant symbols, religious symbols, family symbols, flags, superheroes, animal and plant life, etc.. Schools were also equipped with figures directly related to the $9 / 11$ attacks including emergency vehicles, planes, rescue workers, the World Trade Center and Statue of Liberty. These particular figures provided the students with opportunities to express hidden tensions, pain, conflict, emotions and various other feelings and experiences that may be associated with the trauma of the $9 / 11$ attacks.

We also evaluated the presence of specific themes of interest. In total, there were 545 themes coded in our specific categories of interest. The most common themes were "loss, lack of connection and symbols of support". The themes of "loss, struggle, and lack of connection" were higher in the beginning sessions then as the sandplay therapy progressed, the frequency of these themes decreased over time. In contrast, "the symbols of support" were infrequent in the beginning session then increased after the first session. These changes in the frequency of the themes represent shifts in the students' psychological healing process and reveal that they are improving over time.

Several students also had themes associated with the 9/11 attacks. The presence of these themes underscores the relevance of this tragedy and the continued need for students to express the pain and loss they felt in association to the World Trade Center Attacks. It should also be noted that while many emergent themes may not directly mention the $9 / 11$ attacks but may be indirectly related in terms of students underlying feelings.

\section{Discussion}

\section{Quantitative Results}

As predicted, results from the sandplay intervention positively impacted the academic, behavioral, and psychological outcomes of the students involved. As previously hypothesized, there was an increase in English language and math scores, counselor and teacher ratings, counseling status, and an improvement in attendance. Furthermore, as hypothesized, behavior referrals and suspensions decreased as a result of participating in sandplay therapy. As previously indicated by Mitchell and Friedman (1994), the tactile stimulus of sand can aid in several developmental processes including physical, social, and academic capabilities. In accordance with Mitchell and Friedman (1994), our findings also illustrate significant improvements in the same three areas. The findings indicate a therapeutic intervention such as sandplay; can positively influence a child's learning, actions, and mental health.

Subsequent to the intervention, the children's English language skills increased a total of 40.76 points, indicating that spending one-on-one time with children, even in a recreational environment can help develop their verbal communication abilities. Math scores also improved following the intervention, suggesting that 
within the therapeutic setting, learning and development is taking place. These findings coincide with the research of Russo et al. (2006), proposing that sandplay therapy techniques aid in cognitive development with younger children.

Additionally, the children's counselor and teacher ratings increased as well as the children's status in counseling. Counselor ratings of the students increased by nearly $100 \%$, while the children's status in counseling improved from initial ratings of 1.64 to 2.43 . The original ratings made by the children's teachers had also followed this upward trend, rising from 2.15 to 3.59. It appears that the therapeutic and creative forms of self expression aided in altering the demeanor of the children in ways that were noticeable by their counselors and educational instructors.

Furthermore, contrary to what might have been expected, after the intervention children who experienced the terrorist attacks of 9/11 actually attended school more often and experienced less behavioral reprimands such as referrals and suspensions. Results in the current study help to support the findings of previous studies suggesting that sandplay is within the scope of most trained counselors, provides a low-risk intervention, and has been found to be highly successful therapeutic modality (Carmichael, 1994).

\section{Wounding Theme}

Mitchell and Friedman (1997) found five main considerations, which must be kept in mind during the sandplay process: How the tray is created, the content of the tray, Sandplay series, Sandplay story, and Therapist's feeling responses. Additionally, two main themes arise during the healing processes; the first of the two being "wounding". The wounding theme was most applicable to the present study due to the fact that it involves trays from clients who have experienced such $9 / 11$ related tragedies as trauma, loss, and death of a family member (Mitchell \& Friedman, 1997). In occurrence with Mitchell and Friedman (1997), wounding themes developed, evolved, and changed in positive ways during the sandplay process.

Throughout the present study, coding was taking place to identify and track the progress of wounding themes. As predicted, the wounding themes identified decreased and became more positive throughout the therapeutic process. As previously noted, the starting total of 67 wounding themes reduced to a total of 33 by the eighth session of sandtray therapy, indicating a minute amount of therapy is necessary to obtain a positive change. Wounding themes experienced the largest decline in comparison to transformational and sandplay themes. This indicates that during the therapeutic process negative feelings and emotions decreased, lessened in intensity, and became more positive overall.

\section{Summary}

Our findings highlight the positive impact of sandplay therapy on students' academic, behavioral, and psychological development. Specifically, this evaluation reveals that students who participate in sandplay therapy have increased English language and math scores, more positive counselor and teacher ratings, improved counseling status, and improved attendance as a result of this therapeutic intervention. Similarly, we also found that students' behavioral referrals and suspensions decreased as a result of their participating in sandplay sessions.

In addition, in depth analysis of each sandplay session revealed a strong presence of wounding, transformational, and specific themes. The frequency and flow of these themes meets expectations based on the sandplay literature and are indicators that the students are following a predicted process of psychological healing. 


\section{Implications}

Our findings emphasize the cultural relevance for using sandplay therapy as an effective method for working with ethnic and racial minority students. Given that ethnic minority youth, and Chinese youth in particular, may be reluctant to seek help and utilize traditional mental health services, sandplay therapy offers a culturally responsive, symbolic form of therapeutic healing. In addition, many ethnic minority youth may not feel comfortable openly expressing their emotions, so being able to use figures and symbols in a creative play format allows them to non verbally express themselves around critical emotional and relational issues.

As stated, many of the students in our sample are recent Chinese and other Asian immigrants who may not yet be fluent in the English language. Because sandplay therapy does not rely on direct verbal communication, these students are still able to connect with the counselor and actively participate in the sandplay sessions without concern about their English language expression. They are able to do this in a way that helps them deal with emotional content in their lives. Through this process, the students in our sample were also able to improve their social, behavioral, and academic skills.

Finally, it is clear from our data and from case reports from the various school counselors, that sandplay therapy is an effective and culturally sensitive method for addressing emergent issues associated with the September 11th attacks in New York. While the schools were initially reluctant to embrace the use of sandplay therapy with the ethnic minority elementary school students in our sample, this means of therapeutic intervention was eventually integrated with strong success. As a result, sandplay therapy shows implications that it could be successfully used in trauma and crisis counseling in the future. As revealed in our data, students expressed many emotions and difficult experiences, which are likely associated with the $9 / 11$ attacks. Moreover, there were several occasions when students in our sample used specific symbols and miniatures directly related to the World Trade Center Attacks, further underscoring the continued importance of this historical event.

\section{References}

Borrero, N. E., Yeh, C. J., Tito, P., \& Luavasa, M. (2010). Alone and in between cultural worlds: Voices from Samoan students. Journal of Education, 190(3), 47-56.

Bradway, K., \& McCoard, B. (1997). Sandplay-silent workshops of the psyche. London/New York: Routledge.

Carmichael, K. (1994). Sand play as an elementary school strategy. Elementary School Guidance \& Counseling, $28(4), 302$.

Cook, A., Spinazzola, J., Ford, J., Lanktree, C., Blaustein, M., Cloitre, M., ... van der Kolk, B. (2005). Complex trauma in children and adolescents. Psychiatric Annals, 35(5), 390-398.

Inman, A. G., Yeh, C. J., Madan-Bahel, A., \& Nath, S. (2007). South Asian families: Bereavement and coping post-9/11. Journal of Multicultural Counseling and Development, 35, 101-115.

Kalff, D. (1980). Sandplay: A psychotherapeutic approach to the psyche. (W. Ackerman, Trans.) Santa Monica: Sigo Press. (Original work published 1966).

Kimura, H. (1982). Enuresis nocturna, 11-year old girl. In H. Kawai, \& Y. Yamanaka (Eds.), Studies of sandplay therapy in Japan $I$ (pp. 86-106). Tokyo: Seishin-Shoboh.

Kitanaka, J. (2003). Jungians and the rise of psychotherapy in Japan: A brief historical note. Transcultual Psychiatry, 40(2), 239-247.

Lacroix, L. (2002). Creative sensorielle par l' utilization de jeu de sable en art-therapie. Prisme.

Lacroix, L., Rousseau, C., Gauther, M., Singh, A., Giguere, N., \& Lemzoudi, Y. (2007). Immigrant and refugee preschoolers' sand play representation of the tsunami. The Arts of Psychotherapy, 34(2), 99-113. http://dx.doi.org/10.1016/j.aip.2006.09. 006

Lu, L., Petersen, F., Lacroix, L., \& Rousseau, C. (2010). Stimulating creative play in children with autism through sandplay. The Arts in Psychotherapy, 37(1), 56-64. 
Lusebrink, V. B. (2004). Art therapy and the brain: An attempt to understand the underlying processes of art expression in therapy. Art Therapy, 21(3), 125-135.

Mantele, O. (in press). A child's grief process through Sandplay. In B. Caprio (Ed.), Sandplay: Coming of age. Paper presented at the Los Angeles Sandplay Association 1991 Conference.

Mitchell, R. R. (2005). The sandplay journey. New York, N.Y.

Mitchell, R. R., \& Friedman, H. S. (1994). Sandplay past, present \& future. London: Routledge Press.

Mitchell, R. R., \& Friedman, H. S. (2003). Using sandplay in therapy with adults. In C. E. Schaefer (Ed.), Play therapy with adults. Hoboken, N.J.: John Wiley \& Sons, Inc..

Noyes, M. (1981). Sandplay imagery: An aid to teaching reading. Intervention in School and Clinic, 17(2), $231-237$. doi:10.1177/105345128101700218

Preston-Dillon, D. (2008). Sand therapies: Sandplay and sandtray. Association for Play Therapy. Retrieved from: www.a4pt.org/download.cfm?ID=24669

Reed, J. P. (1975). Sand magic experience in miniatures: A non-verbal therapy for children. Albuquerque: JPR Press

Rousseau, C., Lacroix, L., Singh, A., Gauthier, M. F., \& Benoit, M. (2005). Creative expression workshops in school: Prevention programs for immigrant and refugee children. Canadian Child and Adolescent Psychiatry Review, 14(3), 77-80.

Rousseau, C., Benoit, M., Lacroix, L., \& Gauthier, M. (2009). Evaluation of a sandplay program for preschoolers in a multiethnic neighborhood. Journal of Child Psychology and Psychiatry, 50(6), 743-750.

Russo, M., Vernam, J., \& Wolbert, A. (2006). Sandplay and storytelling: Social constructivism and cognitive development in child counseling. The Arts in Psychotherapy, 33(3), 229-237. http://dx.doi.org/10.1016/j.aip.2006.02.005

Shea, M., \& Yeh, C. J. (2008). Asian American students' cultural values, stigma, relational self-construal: Attitudes toward professional help-seeking. Journal of Mental Health Counseling, 30(2), 157-172.

Shen, Y., \& Armstrong, S. A. (2008). Impact of group sandtray therapy on the self esteem of young adolescent girls. The Journal for Specialists in Group Work, 33(2), 118-137. doi:10.1080/01933920801977397

Shih, Y., Kao, S., \& Wang, W. (2006). The process study of the sandplay therapy on oppositional defiant disorder. Chinese Annual Report of Guidance and Counseling, 19, 41-72.

Steele, S. (2006). When cognitive interventions fail with children of trauma: Memory, learning, and trauma interventions. Retrieved from http://www.tlcinst.org/cognitiveinterventions.html

Takano, S. (1982). Schizophrenia, 21-year-old male. In H. Kawai, \& Y. Nakai (Eds.), Studies of sandplay therapy in Japan I (pp. 1964-84). Tokyo: Seishin-Shoboh.

Weinrib, E. L. (1983). Images of the self: The sandplay therapy process. Boston: Sigo Press.

Winter, R. (2008). Group training in a crisis: An urgent response to 9/11. In H. S. Friedman, R. Mitchell, H. S. Friedman, \& R. Mitchell (Eds.), Supervision of sandplay therapy (pp. 151-167). New York, N.Y., US: Routledge/Taylor \& Francis Group.

$\mathrm{Xu}$, J., \& Zhang, R. (2008). A case study of the sandplay therapy for an 11-year-old girl with selective mutism. Psychological Science (China), 31(1), 126-132.

Xu, J., Zhang, R., \& Zhang, W. (2008). Process and effect of an ADHD boy's sandplay therapy. Chinese Journal of Clinical Psychology, 16(4), 440-442.

Yamanaka, Y. (1982). Depressive hypochondriasis, 72-year-old female. In H. Kawai, \& Y. Yamanaka (Eds.), Studies of sandplay therapy in Japan I (pp. 107-127). Tokyo: Seishin-Shoboh.

Yeh, C. J., Borrero, N. E., Lusheck, C., Plascencia, L., Kiliona, K., Mase, M., ... \& Tito, P. (2014). Fostering social support, leadership competence, community engagement, and resilience among Samoan American youth. Asian American Journal of Psychology, 6, 145-153.

Yeh, C. J., Borrero, N. E., Tito, P., \& Petaia, L. S. (2014). Intergenerational stories of "othered" youth through insider cultural knowledge and community assets. The Urban Review, 46, 147-168.

Yeh, C. J., Inman, A., Kim, A. B., \& Okubo, Y. (2006). Asian American collectivistic coping in response to 9/11. Cultural Diversity and Ethnic Minority Psychology, 12, 134-148.

Yeh, C. J., Kim, A. B., Pituc, S. T., \& Atkins, M. (2008). Poverty, loss, and resilience: The story of Asian immigrant youth. Journal of Counseling Psychology, 55, 34-48. 